\title{
A family with multiple musculoskeletal abnormalities
}

\author{
$\mathrm{K}$. E. BARBER, ${ }^{1} \mathrm{P}$. J. GOW ${ }^{1}$ A ND K. M. MA Y O ${ }^{2 *}$ \\ From the Departments of ${ }^{1}$ Rheumatology and ${ }^{2}$ Radiology, Middlemore Hospital, Auckland, New Zealand
}

SUMMARY A family with multiple musculoskeletal abnormalities is reported. The disorder is characterised by platyspondyly, abnormality of the upper femoral epiphyses, and the development of precocious osteoarthritis. It is proposed that this family represents an example of autosomal dominantly inherited spondyloepiphyseal dysplasia tarda (SED tarda).

This study was initiated by the admission to hospital of a 54-year-old woman (II-6, Fig. 1) for her second total hip joint replacement. The marked degree of cartilage loss in many joints, and the presence of a strong family history of musculoskeletal abnormalities, prompted a detailed study of other family members.

\section{Patients and methods}

All living affected and many unaffected family mem- bers were interviewed and examined. Examination included measurement of he ight and upper and lower body segments. A standing lateral $x$-ray of the thoracic and lumber spine to screen for platyspondyly was performed.

\section{Results}

The mean height $(164 \mathrm{~cm})$ was the same in both the affected and unaffected groups. However, all affected family members had a shorter trunk and
I
II

III

IV

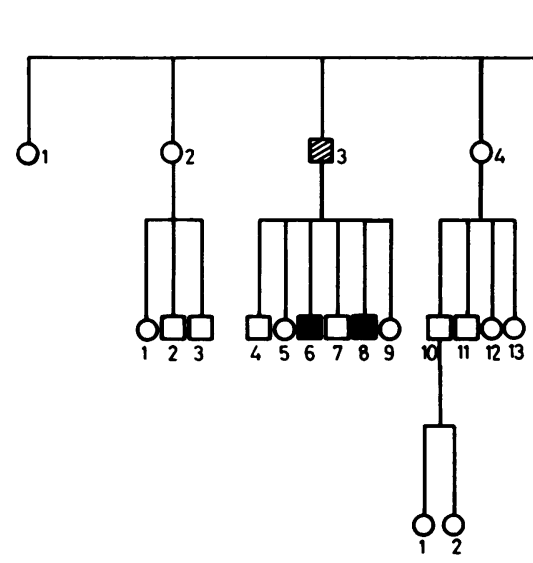

OFEMALE DMALE

Fig. 1 Pedigree of family.

Accepted for publication 5 April 1983.

Correspondence to Dr P. J. Gow, Middlemore Hospital, Otahuhu, Auckland 6, New Zealand.

* Deceased September 1981. 
Table 1 Summary of clinical findings

\begin{tabular}{|c|c|c|c|c|}
\hline Subject & Age (yr) & Joints involved & $\begin{array}{l}\text { Age of } \\
\text { onset (yr) }\end{array}$ & Additional information \\
\hline I-1 & Died 65 & Spine, hips, shoulders & 20 & Post-mortem 'Arthritis most marked in spine' \\
\hline II-3 & Died 47 & Back, hips, knees, shoulders & 20 & - \\
\hline 6 & 54 & Back, hips, knees, shoulders & 3 & Bilateral total hip joint replacement \\
\hline 8 & 46 & Hips & 15 & L total hip joint replacement \\
\hline III-6 & 23 & Back, hips & 3 & 'Perthes's disease' \\
\hline 21 & 29 & Hips, shoulders, elbows & 2 & $\begin{array}{l}\text { Bilateral congenital hip disiocation, bilateral } \\
\text { total hip joint replacement, osteochondritis } \\
\text { dissecans } \mathrm{R} \text { elbow }\end{array}$ \\
\hline 23 & 26 & Back, hips & 6 & - \\
\hline 24 & 27 & Hips, knees, elbows & 3 & Traumatic synovitis $R$ hip and knee \\
\hline 31 & 23 & Back, hips, elbow & 5 & Osteochondritis dissecans L elbow \\
\hline 34 & 15 & Hips & 4 & - \\
\hline
\end{tabular}

longer lower limbs than those not affected, with a reduced upper- to lower-body segment ratio (mean 0.83 against 0.95 ).

The clinical findings in affected family members are summarised in Table 1. Bilateral hip pain invariably occurred, and symptoms in the back, knees, shoulders, and elbows also featured prominently. The age of onset of symptoms ranged from 2 to 20 years, and most of the affected people had been noted to have a stiff gait prior to the onset of pain.

Subject III-6 had been treated for presumed Perthes's disease during childhood, subject III-21 was treated for bilateral congenital dislocation of the hip, and subject III-24 was diagnosed as having traumatic synovitis of the right hip and knee when aged 3 years. Bone fragments resulting from osteochondritis dissecans had been surgically removed from subjects III-8, III-21, and III-31.

Physical examination revealed restriction of movement in affected joints with no associated extraskeletal features.

$X$-rays of the spine in all living affected members showed platyspondyly (Fig. 2), whereas those lacking symptoms had normal vertebral bodies, including subject III-13, a young woman who had been treated for scoliosis in childhood with the insertion of a Harrington rod but did not have any other joint symptoms. Hip $x$-rays of affected individuals in childhood showed irregularity of the femoral heads (Fig. 3) and in adulthood the development of degenerative changes (Fig. 4). $X$-rays of other painful joints in the propositus showed degenerative changes (Figs. 5, 6) in sites not usually affected by primary osteoarthritis.

\section{Discussion}

The findings presented are consistent with a diagnosis of dominantly inherited spondyloepiphyseal dysplasia tarda. SED tarda has been reported as hav-

Fig. 2 Subject III-6. Age 23 years. Lateral view of thoracic spine showing platyspondyly. 


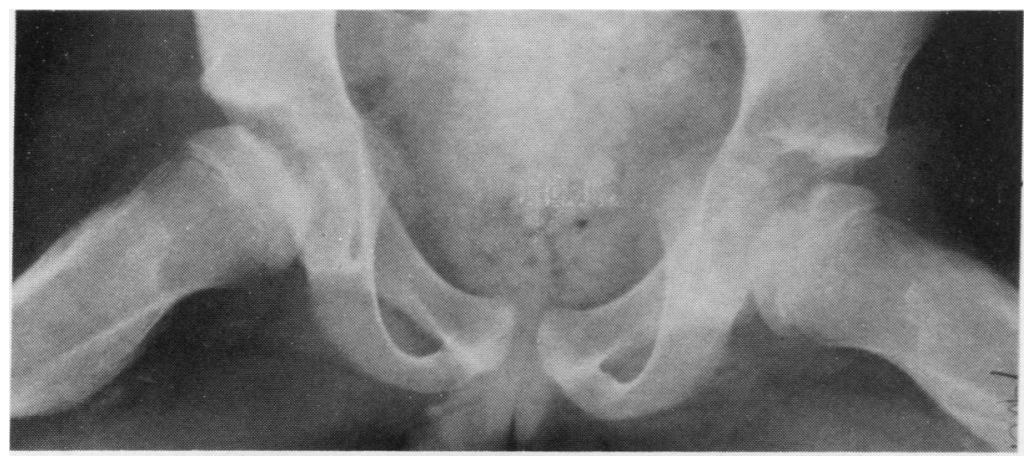

Fig. 3 Subject III-34. Age 10 years. Anteroposterior view of pelvis showing the abnormal contour of both upper femoral epiphyses.

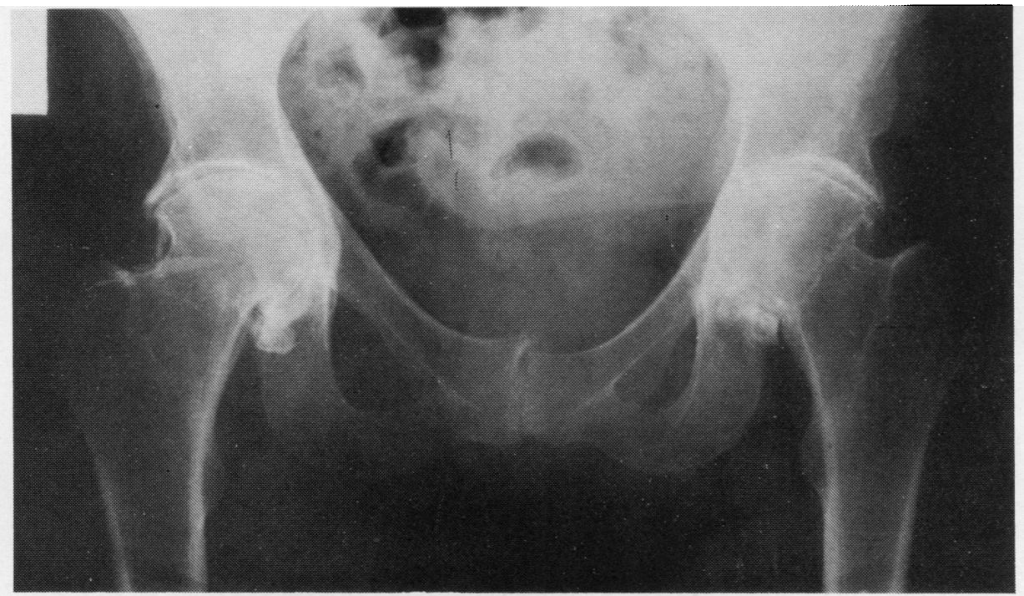

Fig. 4 Subject II-6. Age 53 years. Anteroposterior view of pelvis showing severe loss of hip joint cartilage.

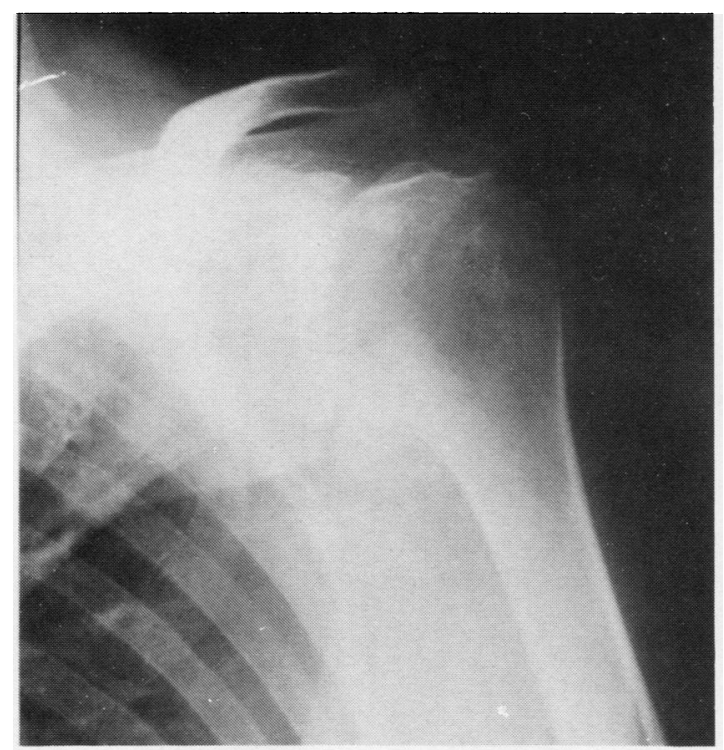

Fig. 5 Subject II-6. Age 50 years. Anteroposterior view of left shoulder showing severe loss of joint cartilage and flattening of the humeral head. ing 3 modes of transmission. The $\mathrm{X}$-linked recessive form was the first mode, described by Maroteaux et al. ${ }^{1}$ More recently both autosomal recessive ${ }^{2}$ and autosomal dominant ${ }^{2-6}$ forms have been described. The latter are similar to the family presented, with autosomal dominant inheritance, and skeletal changes are usually limited to the vertebrae and proximal epiphyses. There is mild truncal shortening, with little kyphosis or dwarfing. Symptoms are usually noted between the fourth and tenth years of life, when affected persons complain of hip pain and may have a stiff gait. Ocular abnormalities, though not present in the reported family, have been described. ${ }^{7}$

$X$-rays show platyspondyly, particularly in the thoracic region, with wedging of the vertebral bodies, but not the mound of dense bone in the central and posterior portions of the flattened vertebrae which characterises the recessive form of SED tarda. Irregularities of the proximal epiphyses, most commonly the upper femoral epiphyses, are usually present, with progressive deformity and the development of degenerative changes. The short tubular bones may or may not be affected. 


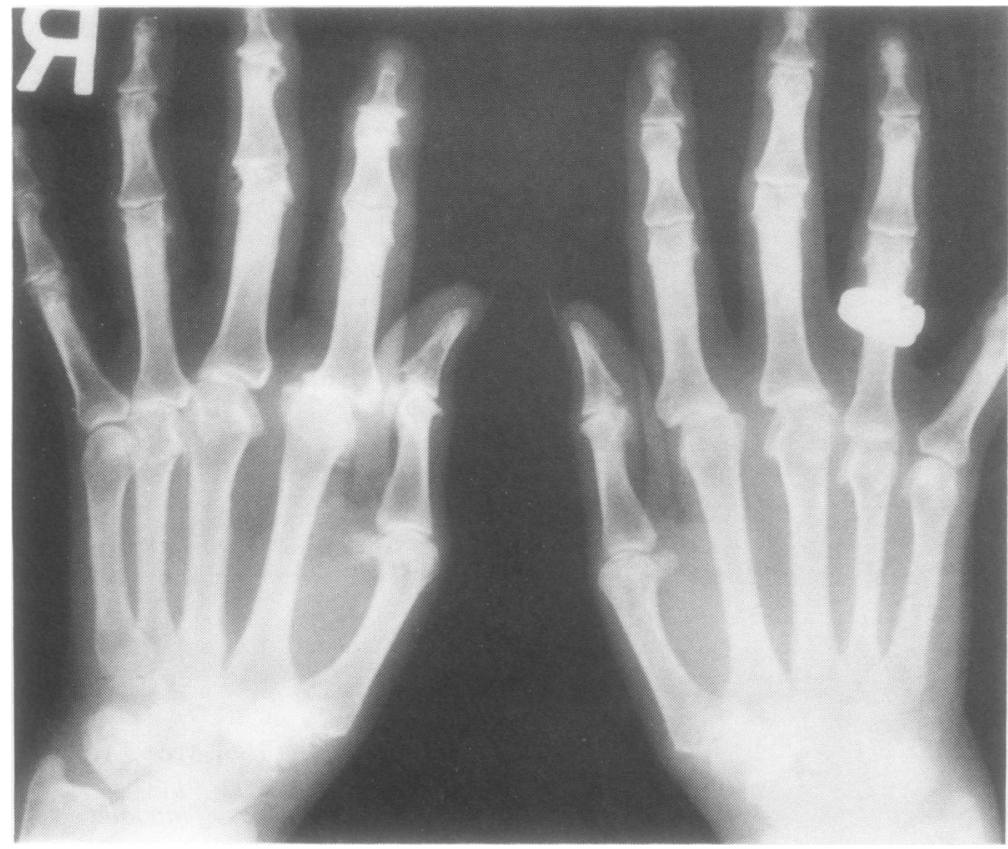

Fig. 6 Subject II-6. Age 50 years. $\mathrm{X}$-ray of hands showing moderately severe degenerative changes.

The development of precocious osteoarthritis is not an uncommon problem. When spondyloepiphyseal involvement predominates, the differential diagnosis includes spondyloepiphyseal dysplasia congenita, Morquio's disease and other mucopolysaccharidoses, chondrodysplasia punctata, Dyggve-Melchior-Clausen dysplasia, hypothyroidism, and Kashin-Beck disease.These entities are well defined, usually presenting with developmental abnormalities in childhood. Multiple epiphyseal dysplasia, which is almost always inherited as an autosomal dominant, presents in a similar manner to SED tarda, but $x$-rays of the spine show that changes, if present, are confined to the edges of the vertebral bodies without any effect on vertebral height, and there is prominent involvement of the distal as well as the proximal skeleton.

This study illustrates the importance of the family history in determining the cause of degenerative arthritis when it occurs in unusual sites or at a young age. Although epiphyseal dysplasias are relatively uncommon, awareness of their place in the differen- tial diagnosis of osteoarthritis may well prevent the inappropriate treatment of musculoskeletal complaints, particularly in childhood.

We are grateful to Dr R. J. M. Gardner for his helpful comments and to Mrs D Gould for typing the manuscript.

\section{References}

1 Maroteaux P, Lamy M, Bernard J. La dysplasie spondyloépiphysaire tardive. Presse Med 1957; 65: 1205-8.

2 Spranger J, Langer L O. Spondyloepiphyseal dysplasias. Birth Defects 1974; 10: 19-61.

3 Moldauer M, Hanelin J, Bauer W. Familial precocious degenerative arthritis and the natural history of osteochondrodystrophy. In: Blumenthal HT, ed.Medical and clinical aspects of aging. New York: Columbia University Press. 1962: 226-33.

4 Rubin P. Modelling errors of the epiphysis. In: Dynamic classification of the bone dysplasias. Chicago: Year Book Medical Publishers, 1964: 106.

5 Carter $\mathrm{CO}$, Sutcliffe J. Genetic varieties of spondyloepiphyseal dysplasia. In: Jellife A M, Stickland B, eds. Symposium ossium. Edinburgh: Livingstone, 1970: 218-24.

6 Diamond L S. A family study of spondyloepiphyseal dysplasia. J Bone Joint Surg 1970; 52A: 1587-94.

7 MacDessi J J, Kozlowski K, Posen S. Spondyloepiphyseal dysplasia with ocular changes. Pediatr Radiol 1978; 7: 220-8. 